Eur. J. Clin. Chem. Clin. Biochem.

Vol. 29, 1991, pp. 395-399

(C) 1991 Walter de Gruyter \& Co. Berlin · New York

\title{
Rapid Diagnosis of Familial Defective Apolipoprotein B-100
}

\author{
By J. Geisel ${ }^{1}$, T. Schleifenbaum ${ }^{1}$, B. Weißhaar ${ }^{2}$ and K. Oette ${ }^{1}$ \\ 1 Institut fïr Klinische Chemie, Universität zu Köln \\ ${ }^{2}$ Max-Planck-Institut für Züchtungsforschung, Abteilung Biochemie, Köln
}

(Received November 29, 1990/March 1, 1991)

Summary: A method is described for the rapid, economic and non-radioactive examination of DNA samples from hypercholesterolaemic patients for familial defective apolipoprotein B-100, using a modified polymerase chain reaction (PCR) protocol and restriction enzyme isoform genotyping. Because of the high prevalence of familial defective apolipoprotein B-100, which is estimated to be one in 500 in most screened general populations, interest is focussed on a simple method for detection of this point mutation. In our protocol a diagnostic restriction site is created by PCR, using a specifically designed partly mismatched primer. In the case of familial defective apolipoprotein B-100 the amplified DNA segment contains an additional $S c a$ I site, whereas DNA amplified from the normal allele is resistant to Scal digestion. A rapid differentiation between the two alleles is achieved by agarose gel electrophoresis of the ScaI-digested PCR product.

\section{Introduction}

Epidemiological studies have demonstrated that elevated levels of plasma cholesterol, particularly low density lipoprotein (LDL) ${ }^{1}$ ) cholesterol, are associated with an increased risk of premature coronary heart disease $(1-3)$. The concentration of LDL-cholesterol is to a large extent regulated by the interaction between apolipoprotein B=100-containing LDL particles and LDL receptors $(4,5)$. Different genetic defects in the LDL receptor gene reduce the removal of $\mathrm{LDL}$ particles via the LDL receptor pathway and lead to the disorder of familial hypercholesterolaemia (6). However, in some patients with primary hypercholesterolaemia, clearance of LDL particles from the circulation is reduced, whereas the LDL receptor function is normal $(7,8)$. When LDL particles isolated from these patients are used in binding studies with normal LDL receptors of human fibroblasts, they are found to have a markedly reduced binding activity in comparison with normal LDL particles.

') Abbreviations: LDL, low density lipoprotein; PCR, polymerase chain reaction.
Apolipoprotein B-100 is the sole protein component of LDL particles and the ligand that is recognized and bound to the LDL receptor. To identify the defect responsible for the reduced receptor binding, the apolipoprotein B-100 gene from one proband with the binding defect was sequenced (9). At the DNA level, the change of a single nucleotide trom $G$ to $A$ was identified at position 10708 in exon 26, resulting in the replacement of arginine by glutamine at amino acid position 3500 . In the families studied, the mutant allele was always associated with hypercholesterolaemia and binding-defective LDL particles. This indicated that this mutation is phenotypically inherited in an autosomal dominant fashion. The hypercholesterolaemia associated with this point mutation in the apolipoprotein B-100 gene has been designated familial defective apolipoprotein B-100 (9).

The frequency of this disorder has been determined in several studies $(10-13)$. With the exception of a Finnish population, where this mutation was not detected, the prevalence of this disorder was one in 500 in the screened general populations. The frequency of familial defective apolipoprotein B-100 is similar to 
classical familial hypercholesterolaemia, making it one of the most common single-gene mutations responsible for a clinical abnormality. A rapid assay for examining DNA for this mutation will therefore be very useful.

A method for detecting this point mutation using specific oligonucleotides has been published (9). In the described procedure, the DNA is immobilised on a nylon membrane after amplification by $\mathrm{PCR}^{1}$ ), then hybridised with radiolabelled allele-specific oligonucleotides. This hybridisation procedure is costly and time consuming. In this report, we describe restriction isotyping (restriction enzyme isoform genotyping) as a simpler and faster method for the diagnosis of familial defective apolipoprotein B-100.

\section{Materials and Methods}

Amplification of apolipoprotein B-100 sequences from genomic DNA for restriction isotyping

Total genomic DNA was derived from white blood cells by using a Triton X-100 lysis method (14). The reaction was started with approximately $1 \mu \mathrm{g}$ DNA in a buffer containing $10 \mathrm{mmol} / 1$ Tris- $\mathrm{HCl}$, pH 8.3, $50 \mathrm{mmol} / 1 \mathrm{KCl}, 2.5 \mathrm{mmol} / 1 \mathrm{MgCl}_{2}, 1 \mathrm{~g} / 1$ gelatine, $0.25 \mathrm{mmol} / \mathrm{l}$ of each nucleotide (BRL, Eggenstein, F.R.G.), $66.6 \mathrm{nmol} / 1$ of each primer and 2.5 units Taqpolymerase $^{2}$ (Perkin-Elmer Cetus, Langen, F. R. G.) in a total volume of $100 \mu$. The initial number of templates of a single copy gene in $1 \mu \mathrm{g}$ genomic DNA is estimated to be $3 \times 10^{5}(15)$. Both primers were 25 nucleotides in length. The sequences of the primers are listed in figure 1. The downstream primer P2 contains the two mismatches forming a part of a Scal restriction enzyme ${ }^{2}$ ) recognition site.

\section{3) Enzymes:}

ScaI from Streptomyces caespitosus,

Taq DNA polymerase from Thermus aquaticus
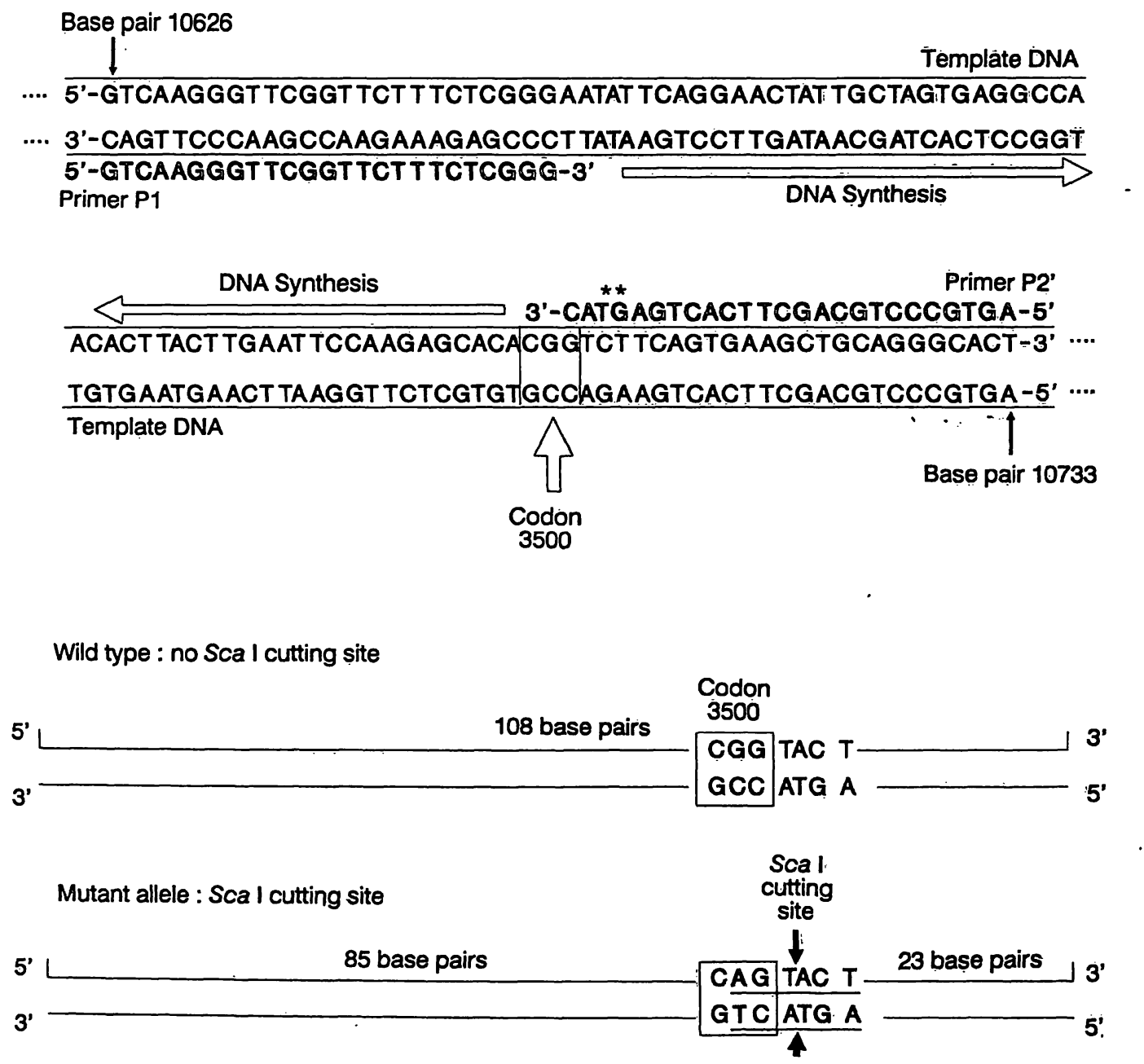

Fig. 1. New restriction polymorphism created by the point mutation at codon 3500 and modified PCR using mismatched primers. ** Mismatched nucleotides.

At the top, the sequences of the amplified DNA and the used primers are shown. The downstream primer contains the two designed mismatches that are part of the Scal restriction enzyme recognition site. In the lower part of the figure, the sizes of the amplified fragments and the cleaved products are demonstrated. The ScaI restriction recognition site is underlined. 
DNA was amplified by using the PremIII Thermocycler (BIOzym diagnostic, Hameln, F. R.G.). PCR was started with an initial denaturing step at $94^{\circ} \mathrm{C}$ for 2 minutes, followed by annealing at $55^{\circ} \mathrm{C}$ for 1 minute and extension at $72^{\circ} \mathrm{C}$ for 1 minute. The next 30 cycles were performed likewise, except that the denaturing time was changed to 1 minute.

To ascertain the success of PCR amplification, $15 \mu \mathrm{l}$ of the reaction product was electrophoresed on an agarose gel (Sigma, Deisenhofen, F. R. G.), $30 \mathrm{~g} / \mathrm{l}$, for 1 hour at a constant current (100 mA).

Restriction isotyping of amplified apolipoprotein B100 sequences with $S c a l$, and gel analysis

After PCR amplification, 5 units of Scal (Boehringer, Mannheim, F.R.G.) were added directly to $18 \mu \mathrm{l}$ of the reaction mixture for digestion of the apolipoprotein B-100 sequences. Purification of the PCR product was not necessary. The resulting DNA fragments were separated in an agarose gel $\mathrm{(Nu}-$ sieve 3:1; FMC BioProducts, Hameln, F. R. G.), $40 \mathrm{~g} / \mathrm{l}$, stained with ethidium bromide. After electrophoresis. the DNA fragments were visualized by UV illumination. The size of the $S c a l$ fragments was estimated by comparison with a molecular weight DNA-marker (BRL, Eggenstein, F. R. G.).

\section{Results}

The basic experimental approach is illustrated in figure 1. In the first step of the analysis, a 108 base pair region of the apolipoprotein B-100 gene from position 10626 to 10733 is amplified by PCR. This region contains the position 10708, which is crucial for familial defective apolipoprotein B-100. The primer P2, used for PCR amplification, is designed to obtain 2 changes in the original DNA sequence. These mismatched nucleotides and the nucleotide at the site of the point mutation in apolipoprotein B-100 are part of the recognition sequence of the $S c a$ I restriction enzyme. The primer P1 is complementary to the nucleotide sequence 10626 to 10650 , and primer 2 to the nucleotide sequence 10709 to 10733 . Under the reaction conditions used, specific amplification was observed with DNA from all subjects tested.

The second step is the digestion of the amplified DNA fragment with $S c a$ I and subsequent agarose gel electrophoresis. Amplified segments will contain the enzyme cleavage site only if they are derived from the mutated locus. An 85 base pair fragmient is formed upon cleavage with $S c a$ I (fig. 2). The PCR products derived from the normal allele contain the introduced mismatched nucleotides, but lack the $S c a$ I restriction site because of the difference at the mutated position. In this case only the 108 base pair segment can be detected after gel electrophoresis (fig. 2). To exclude the possibility of false positive results, the gel was overloaded in several instances with PCR products, of the normal allele after enzyme digestion, but no additional fragments were observed.

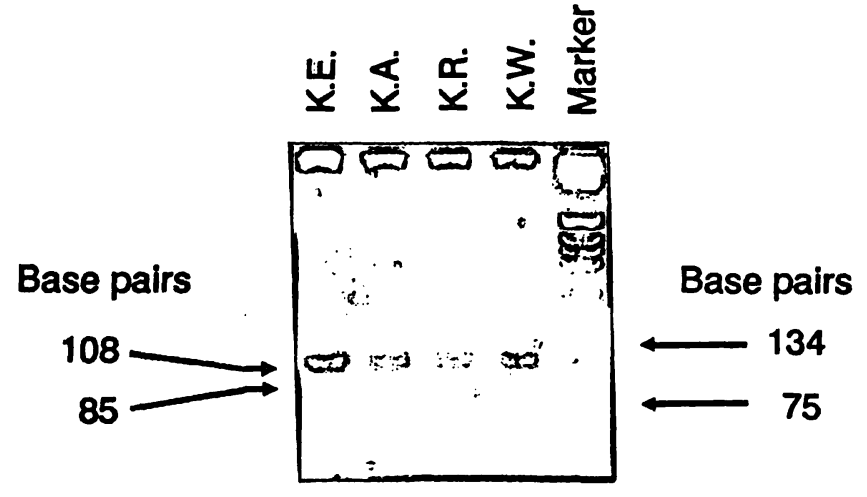

Fig. 2. Electrophoresis of ScaI-digested PCR products. $18 \mu \mathrm{l}$ of the amplified DNA samples were directly digested with Scal and electrophoresed on a NuSieve agarose gel, $40 \mathrm{~g} / \mathrm{l}$. In the subjects K. R. and K. A., the 108 and 85 base pair-fragments were detected, indicating that these individuals were heterozygous for the familial defective apolipoprotein B-100 mutation. In K. E. and $\mathrm{K}$. W. only the 108 base pair-fragment was found, demonstrating the homozygosity of the wild type allele. The subjects are the same as those shown in figure 3.

To verify our approach, DNA from a patient with published familial defective apolipoprotein B-100, characterized with allele-specific oligonucleotides (patient 1 in reference 11) was amplified and digested with $S c a$ I. The additional ScaI cleavage site was detected in the PCR product, indicating that this patient had familial defective apolipoprotein B-100. These results demonstrate that the sensitivity of both methods is equivalent.

With the described method, we identified other individuals with familial defective apolipoprotein B-100 (manuscript in preparation). An example of the inheritance of the mutation is demonstrated in figure 3. The mutation was identified in all hypercholesterolaemic family members, while in normolipidaemic individuals only the wild type allele was found.

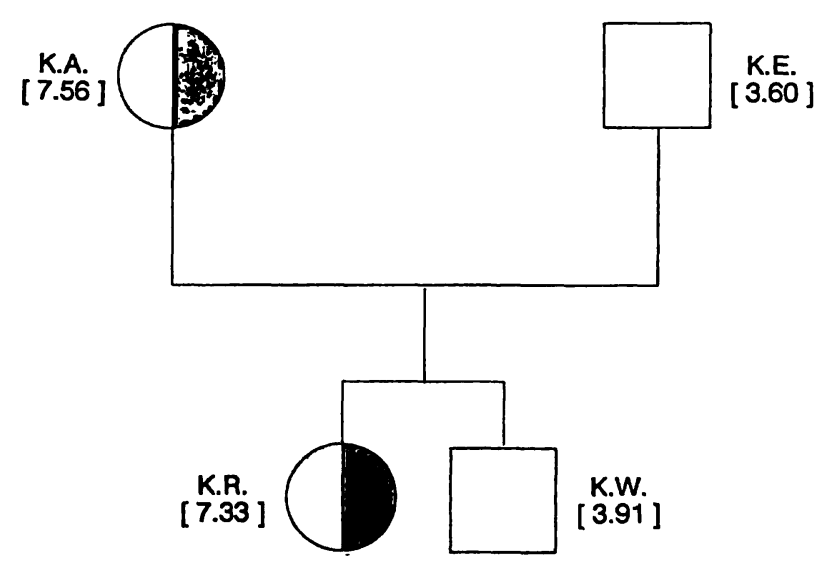

Fig. 3. Pedigree of a family with familial defective apolipoprotein B-100.

LDL cholesterol (mmol/l) is given in brackets.

The corresponding PCR products are presented in figure 2. 


\section{Discussion}

Previous methods for the determination of familial defective apolipoprotein B-100 were based on the use of allele-specific oligonucleotide probes. This method relies on the use of radioactivity and depends on stringent hybridization and washing conditions to discriminate between alleles, and it poses many technical constraints in routine diagnostic applications. Another technical approach is based on the selective amplification of the mutated allele (16). With a primer complementary to the mutated sequence, amplification of the mutated allele is possible, whereas the primer mismatch with the wild type allele stops the amplification process. Because of the possibility of a non-selective amplification of the normal allele, very stringent PCR conditions are needed. Our method does not differentiate between the mutated and wild type alleles during PCR, which results in reduced susceptibility. The same base substitutions were introduced into both alleles, resulting in the formation of a restriction site only in one case.

If a new restriction site is created during PCR amplification, two strategies exist for designing a partly mismatched primer $(17-19)$. First, the restriction site is present only in the amplified mutated allele or, second, the restriction site is absent in the mutated allele and present in the normal allele. Here we preferred the first approach, because it avoids the generating of false positive results due to incomplete digestion. To minimize the possibility of false negative results, we tested the efficiency of the digestion step by parallel testing of DNA from patients known to contain the mutation. The mutation was detected in all these controls. In addition, even incomplete digestion of the amplified DNA will result in the production of the differentiating smaller fragment, which indicates the high sensitivity of: pur approach. False positive results can be generated by replication errors of the Taq DNA polymerase, if the diagnostic ScaI recognition site is created by misincorporation of nucleotides into the wild-type allele. But this event is extremely unlikely, because the number of templates in $1 \mu \mathrm{g}$ genomic DNA is very large (15). Statistical calculations to RFLP ${ }^{1}$ ) analysis demonstrate that if 100000 starting templates are used, the replication errors can be neglected; however, they would dramatically increase if only a few templates were used (20).

In the case of familial defective apolipoprotein B-100, the combination of $\mathrm{PCR}$, restriction enzyme digestion and agarose gel electrophoresis offers the possibility of screening individuals in a simple and economical way. If the method is coupled with boiling extraction of DNA samples (21), analysis can be performed within a day.

\section{Acknowledgement}

We thank Dr. Harald Funke, Institut für Klinische Chemie und Laboratoriumsmedizin, Münster, for helpful discussion and comments in preparing the modified primers and Dr. Herbert Schuster, Medizinische Poliklinik der Universität, München, for supplying DNA from a patient with published familial defective apolipoprotein B-100.

\section{References}

1. Stamler, J., Wentworth, D. \& Neaton, J. D. (1986) Is relationship between serum cholesterol and risk of premature death from coronary heart disease continuous and graded? J. Amer. Med. Ass. 256, 2823-2828.

2. Lipid Research Clinics Program. The Lipid Research Clinics Coronary Primary Prevention Trial Results (1984) I. Reduction in incidence of coronary heart disease. J. Amer. Med. Ass. 251, 351-364.

3. Lipid Research Clinics Program. The Lipid Research Clinics Coronary Primary Prevention Trial results (1984) II. The relationship of reduction in incidence of coronary heart disease to cholesterol lowering. J. Amer. Med. Ass. 251, $365-374$.

4. Scott, J. (1989) The molecular and cell biology of apolipoprotein B. Mol. Biol. Med. 6, 65-80.

5. Goldstein, J. L., Brown, M. S., Anderson, R. G. W., Russell, D. W. \& Schneider, W. J. (1985) Receptor-mediated endocytosis: concepts emerging from the LDL receptor system. Ann. Rev. Cell. Biol. 1, 1-39.

6. Brown, M. S. \& Goldstein, J. L. (1986) A receptor-mediated pathway for cholesterol homeostasis. Science 232, 34-47.

7. Vega, G. L. \& Grundy, S. M. (1986) In vivo evidence for reduced binding of low density lipoproteins to receptors as a cause of primary moderate hypercholesterolemia. J. Clin. Invest. $78,1410-1414$.
8. Weisgraber, K. H., Innerarity, T. L., Newhouse, Y. M., Young, S. G., Arnold, K. S., Krauss, R. M., Vega, G. L., Grundy, S. M. \& Mahley, R. W. (1988) Familial defective apolipoprotein B-100: Enhanced binding of monoclonal antibody MB47 to abnormal low density lipoproteins. Proc. Natl. Acad. Sci. USA 85, 9758-9762.

9. Soria, L. F., Ludwig, E. H., Clarke, H. R. G., Vega, G. L., Grundy, S. M. \& McCarthy, B. J. (1989) Association between a specific apolipoprotein $B$ mutation and familial defective apolipoprotein B-100. Proc. Natl. Acad. Sci. USA $86,587-591$.

10. Tybjærg-Hansen, A., Gallagher, J., Vincent, J., Houlston, R., Talmud, P., Dunning, A. M., Seed, M., Hamsten, A., Humphries, S. E. \& Myant, N. B. (1990) Familial defective apolipoprotein B-100: Detection in the United Kingdom and Scandinavia, and clinical characteristics of ten cases. Atherosclerosis 80, 235-242.

11. Schuster, H., Rauh, G., Kormann, B., Hepp, T., Humphries, S., Keller, C., Wolfram, G. \& Zöllner, N. (1990) Familial defective apolipoprotein B-100: Comparison with familial hypercholesterolemia in 18 cases detected in Munich. Arteriosclerosis $10,577=581$.

12. Hämäläinen, T., Palotie, A., Aalto-Setälä, K., Kontula, K. \& Tikkanen, M. J. (1990) Absence of familial defective apolipoprotein B-100 in Finnish patients with elevated serum cholesterol. Atherosclerosis 82, 177-183. 
13. Innerarity, T. L., Mahley, R. W., Weisgraber, K. H., Bersol, T. P., Krauss, R. M., Vega, G. L., Grundy, S. M., Friedl, W., Davignon, J. \& McCarthy, B. J. (1990) Familial defective apolipoprotein B-100: a mutation of apolipoprotein B that causes hypercholesterolemia. J. Lipid Res. 31, 13371349.

14. Kunkel, L. M., Smith, K. D., Boyer, S. H., Borgaonkar, D. S., Wachtel, S. S., Miller, O. J., Breg, W. R., Jones, H. W. \& Rary, J. M. (1977) Analysis of human Y-chromosomespecific reiterated DNA in chromosome variants. Proc. Natl. Acad. Sci. USA 74, 1245-1249.

15. Innis, M. A. \& Gelfand, D. H. (1990) Optimization of PCRs. In: PCR Protocols: A guide 10 methods and applications (Innis, M. A., Gelfand, D. H., Sninsky, J. J. \& White, T. J., eds.) Academic Press, San Diego.

16. Wu, D. Y., Ugozzoli, L. Pal, B. K. \& Wallace, B. (1989) Allele-specific enzymatic amplification of $\beta$-globin genomic DNA for diagnosis of sickle cell anemia. Proc. Natl. Acad. Sci. USA $86,2757-2760$.
17. Kumar, R. \& Barbacid, M. (1988) Oncogene detection at the single cell level. Oncogene 3,647-651.

18. Kumar, R. \& Dunn, L. L. (1989) Designed diagnostic restriction fragment length polymorphisms for the detection of point mutations in ras oncogenes. Oncogene Rescarch $1,235-241$.

19. Haliassos, A., Chomel, J. C., Grandjouan, S., Kruh, J., Kaplan, J. C. \& Kitzis, A. (1989) Detection of minority point mutations by modified PCR technique: a new approach for a sensitive diagnosis of tumor-progression markers. Nucl. Acids Res. 17, 8093-8099.

20. Krawczak, M., Reiss, J., Schmidtke, J. \& Rösler, U. (1989) Polymerase chain reaction: replication errors and reliability of gene diagnosis. Nucl. Acids Res. 17, 2197-2201.

21. Lench, N., Stanier, P. \& Williamson, R. (1988) Simple noninvasive method to obtain DNA for gene analysis. Lancet $I, 1356-1358$.

Dr. J. Geisel

Institut für Klinische Chemie

Universität zu Köln

Joseph-Stelzmann-Straße 9

W-5000 Köln 41

Bundesrepublik Deutschland 
